\title{
Barium Bismuthate Nanoribbons with Good Electrochemical Detection Performance for $\mathrm{Pb}(\mathrm{II})$
}

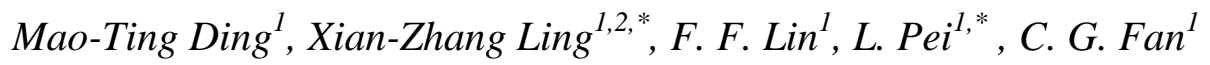 \\ ${ }^{1}$ School of Civil Engineering, Harbin Institute of Technology, Heilongjiang, Harbin 150090, P. R. \\ China \\ ${ }^{2}$ School of Civil Engineering, Qingdao Technological University, Shandong, Qingdao 266520, P. R. \\ China \\ *E-mail: xianzhang_ling@263.net, lzpei1977@163.com
}

doi: $10.20964 / 2017.10 .67$

Received: 4 April 2017 / Accepted: 10 August 2017 / Published: 12 September 2017

\begin{abstract}
A facile hydrothermal process was used for the synthesis of barium bismuthate nanoribbons. The nanoribbons were applied as the sensing materials for sensitive detection of $\mathrm{Pb}(\mathrm{II})$. The micromorphology and structure of the prepared products were analyzed by scanning electron microscopy (SEM) and X-ray diffraction (XRD), respectively. The suspension with barium bismuthate nanoribbons was cast on the surface of a glassy carbon electrode (GCE). The barium bismuthate nanoribbons modified GCE was used for the detection of $\mathrm{Pb}(\mathrm{II})$ using square wave anodic stripping voltammetry (SWASV) technique. The results show that the fabricated GCE exhibited a linear range of 0.001-2 mM with the limit of detection (LOD) of $0.13 \mu \mathrm{M}$. The barium bismuthate nanoribbons modified GCE has a promising potential in practical application for the detection of real samples with water and soil.
\end{abstract}

Keywords: Barium bismuthate nanoribbons, Glassy carbon electrode, Scanning electron microscopy, Electrochemical detection, $\mathrm{Pb}(\mathrm{II})$.

\section{FULL TEXT}

(C) 2017 The Authors. Published by ESG (www.electrochemsci.org). This article is an open access article distributed under the terms and conditions of the Creative Commons Attribution license (http://creativecommons.org/licenses/by/4.0/). 